\title{
EMPODERAMENTO COMO SUPORTE AO DESENVOLVIMENTO REGIONAL
}

\section{EMPOWERMENT AS SUPPORT FOR REGIONAL DEVELOPMENT}

\author{
Jaime Quintanilha Gomes \\ Eletrobras Companhia de Geração Térmica de Energia Elétrica - RS - Brasil
}

\begin{abstract}
Resumo: Este artigo traz à discussão alguns elementos de empoderamento, objetivando potencializar o desenvolvimento sustentável através de ações participativas. Como estratégia de desenvolvimento local, constituiu-se uma transformação da perspectiva dos atores. Através da investigação-ação-participação facilitou-se a construção da organização comunitária. As entrevistas e oficinas de devoluções proporcionaram maior envolvimento social, resultando em maior empoderamento por parte da comunidade local.
\end{abstract}

Palavras-chave: Participação. Capital social. Empoderamento.

Abstract: This paper discusses some elements of empowerment, aiming to enhance sustainable development through participatory activities. As local development strategy, was a transformation from the perspective of actors. Trough research-action-participation facilitated the construction of community organizing. The interviews and workshops provided returns and social involvement, resulting in greater empowerment for the local community.

Key words: Participation. Social joint stock. Empowerment.

\section{Introdução}

Parte-se, neste trabalho, da concepção de território entendido como campo de forças, com ênfase na dimensão relacional que se manifesta nos âmbitos global, regional e local. As territorialidades, resultantes desse processo, são expressões das formas de poder engendradas em cada território e imprimem, nos diferentes lugares, formas próprias de competitividade e de solidariedade que, articuladas, dotam de dinamicidade o todo social. Dessa forma, dialogar, cooperar, empoderar, são componentes de relações que conformam, neste caso desde uma perspectiva local, a dimensão territorial que permeia este trabalho.

Assim, há uma possibilidade de entendimento e de aproveitamento de estratégias políticas participativas desde uma dimensão mais próxima da comunidade. Então, a percepção da territorialidade transforma-se, ajustando-se a esta nova concepção, favorecendo a integração entre alternativas políticas estabelecidas a partir das ações desenvolvidas com caráter endógeno.

Enquanto estudo de caso amparado nesta abordagem, buscou-se compreender uma realidade particular vivenciada pelos atores sociais que habitam as margens do arroio Bagé, mais especificamente os moradores da Rua Marcílio Dias, no bairro do Passo do Onze, na área urbana de Bagé, RS. Partiu-se, de uma perspectiva local, que serviu como suporte à planificação estratégica situacional, 
ou seja, de uma apreciação com enfoque ambiental, social e econômico, que proporcionasse encaminhamentos de ações mais criativas para a recuperação e para a manutenção sustentável do Arroio Bagé. Capturaram-se, através de técnicas de pesquisa participativa, algumas relações entre os atores sociais envolvidos e alguns dos problemas por eles vivenciados.

Utilizou-se uma abordagem qualitativa da realidade em estudo, destacando aspectos de sua formação e situação atual. A partir de uma perspectiva dialética, fundada na investigação-ação-participação, aplicaram-se técnicas de pesquisa como entrevistas, observação participante e oficinas de devoluções, que provocaram e proporcionaram um envolvimento e uma integração social, fomentando e estimulando o empoderamento das pessoas, entendido como ferramenta de promoção de uma transição em direção a uma nova perspectiva ambiental, social e econômica nesta comunidade.

Segundo Chizzotti (2006), a pesquisa participativa tem como pressuposto a democratização da produção do conhecimento e da sociedade, e o desenvolvimento da justiça social. Afirma, ainda, que esse tipo de investigação não é mero conjunto de métodos, meios e técnicas, mas se fundamenta em uma ética e em uma concepção alternativa da produção popular do conhecimento, segundo a qual as pessoas comuns são capazes de compreender e transformar sua realidade. Trata-se, para Chizzotti (2006), de um modelo e de um meio de mudança efetiva para o qual os sujeitos implicados devem elaborar e trabalhar uma estratégia de mudança social. Nesse contexto, o pesquisador assumiu o papel de intermediador do processo de pesquisa, organizando a participação, as condições de discussão e de análise, redigindo ou garantindo o registro da discussão e da decisão que deveria retroalimentar as discussões ulteriores. $O$ trabalho de síntese e o registro das análises e deliberações, que serviram para reuniões subsequentes, foram fundamentais para a elevação dos níveis de conhecimento na ação.

A estratégia que partiu da premissa da importância do processo participativo, a partir de dentro de uma pequena localidade, foi considerada como um embrião, e com possibilidades de contribuição/suporte para o desenvolvimento local em uma perspectiva horizontal, ou seja, o segmento da Rua Marcílio Dias, às margens do arroio Bagé, no bairro do Passo do Onze, no centro da cidade de Bagé.

Partindo-se dessa concepção geral, tratou-se de facilitar condições organizacionais que gerassem o empoderamento dos atores sociais envolvidos; tratou-se também de definir redes de colaboração e ampliá-las, dando suporte ao entendimento desta pequena comunidade, para que os mesmos pudessem refletir, individualmente e coletivamente, e pudessem também protagonizar o seu desenvolvimento, enquanto indivíduos, bem como de sua localidade e, dessa forma, se tornassem capazes de formar parcerias maiores dentro do contexto do nível do desenvolvimento regional, ancorado na participação e na sustentabilidade.

Atualmente, o grande desafio deste local, especificamente, está centrado na população excluída, quer seja do mercado de trabalho, de um ambiente ecologicamente mais saudável ou pela inexistência de uma organização capaz de suprir as necessidades básicas da comunidade de forma participativa. 
Em Bagé, os setores comerciais e prestadores de serviços são, em sua maioria, reflexos das atividades agropecuárias extensivas, praticadas na área rural do município. Ao longo dos últimos cinquenta anos, os produtores que não tiveram acesso aos recursos, devido ao não acompanhamento da modernização, não se ajustaram às condições socioeconômicas, passando a constituir uma categoria excluída da dinâmica do desenvolvimento regional rural. A estrutura agrária no país como um todo e na região em estudo em particular são exemplos típicos da elevada concentração da propriedade da terra e da renda que marca o processo de apropriação e uso da terra no país. Fatores como esses contribuíram para o êxodo rural na região. A prestação de serviços tornou-se a principal atividade geradora de empregos no município, sendo que parte significativa da população que vive na cidade supre as suas necessidades, como habitação, saúde, educação e segurança, com os recursos econômicos oriundos da atividade agropecuária, principal atividade econômica da região da Campanha.

Dentro desse contexto, a comunidade do Passo do Onze buscou encontrar perspectivas de melhorias na qualidade de vida por meio de alternativas, visando suprir algumas de suas carências básicas e, ao mesmo tempo, cooperar para a recuperação do arroio.

Cabe ressaltar que este aspecto de degradação ambiental, social e econômico, encontrado na localidade estudada, pode ser relativizado, considerando que o caso em questão aborda uma realidade que se encontra presente em inúmeras localidades existentes em várias cidades brasileiras onde as políticas públicas disponíveis, em grande parte, têm sido insuficientes para alcançar tais dimensões sociais.

Então, como reverter a perspectiva da qualidade de vida, oriunda de um modelo de desenvolvimento hegemônico excludente, através de uma proposição alternativa, baseada em uma construção coletiva?

A escolha da comunidade investigada justifica-se pelo fato de tratar-se de uma realidade localizada na periferia de um dado espaço urbano com uma quantidade de participantes relativamente controlável para aplicação da metodologia proposta, composta de 23 famílias, somando um total de 49 habitantes.

A escolha da metodologia de investigação-ação-participação deu-se pela necessidade de interação com a comunidade para o desenvolvimento do trabalho, uma vez que prevê formas de abordagens, com processos interativos e de intervenções em localidades.

Como objetivo nesta pesquisa buscou-se encontrar os elementos constituintes do empoderamento humano (organização comunitária, participação e autoestima), na pequena comunidade, a partir de processos participativos. Partiuse da concepção de que o processo de ação-participação favorece a emancipação popular, ou seja, é uma das formas de fomentar o empoderamento, através da reflexão individual e coletiva, acerca de uma dada realidade social e política.

Como hipótese teve que a partir do empoderamento dos atores locais seria possível promover uma nova perspectiva de melhoria de qualidade de vida para que fosse utilizada como instrumento que viabilizasse reverter situações de 
degradação socioambiental e encaminhasse através de um processo de construção coletiva, ações mais criativas de desenvolvimento urbano em prol de um desenvolvimento regional sustentável e participativo.

O enfoque alternativo voltado ao desenvolvimento sustentável vem ao encontro de demandas observadas em toda a região da Campanha, visto que o modelo de desenvolvimento atual dominante vem evidenciando seus limites, no que tange à organização social e econômica, bem como ambiental. A situação de pobreza e exclusão, associada aos problemas ambientais verificados na localidade em questão, dificilmente poderia ser resolvida somente pelo acesso ao crédito, à assistência técnica e à realização de atividades de formação. É uma situação estrutural que se caracteriza por problemas de saúde, trabalho, educação e, principalmente, organização.

As estratégias de formação, facilitação e capacitação entre os habitantes do lugar se realizaram durante todo o período de estudo, prevendo alternativas para a geração de renda, de manejo e conservação dos recursos naturais, propostas coletivas de ações mais criativas, sempre com a participação dos atores sociais. Foram apoiadas as atividades nas quais os habitantes participaram com seus saberes e conhecimentos específicos sobre a localidade. A facilitação e a capacitação, enquanto processos de construção conjunta de conhecimentos foram indispensáveis para o desenvolvimento de um plano sustentável.

O processo desencadeado nesta comunidade, por meio da continuidade de ações coletivas, poderá afirmar uma rede capaz de suportar e encaminhar as soluções dos problemas de outras comunidades às margens do arroio Bagé vinculando-se a instituições estabelecidas da sociedade e conectando-se, assim, a uma esfera regional mais abrangente, tendo em vista que desta práxis se desencadeou uma pequena rede social.

\section{Processo de empoderamento humano na perspectiva de melhoria da qualidade de vida na localidade}

Como elemento central do processo articulado para a consecução e efetivação dos propósitos deste trabalho aparece o capital social.

O capital social emerge como um mecanismo que potencializa os grupos sociais e ou territórios estabelecidos em posições desfavoráveis nas disputas políticas, por poder, recursos econômicos e qualidade de vida. Cumpre um papel central na refundação do contrato social contemporâneo, pois é acessível aos empobrecidos e/ou excluídos que não conseguem ser cidadãos livres e iguais e atuarem numa estrutura comum, pois estão alijados do poder econômico e político (PASE, 2006).

Ao assumirem o protagonismo na promoção do desenvolvimento local, atores sociais têm encontrado caminhos para revitalizar e afirmar as suas próprias organizações sociais, tanto em âmbito urbano quanto rural. Essas organizações vêm sendo atualizadas e renovadas como uma necessidade para o avanço das dinâmicas sociais de inovação. As novas soluções técnicas desenvolvidas 
localmente para a gestão do meio natural cobram soluções organizativas compatíveis diante da complexidade dos ambientes. Monzó (2003) afirma que, ao estabelecer vínculos entre os processos de transformação local e os espaços mais amplos, nos quais são formulados e debatidos os projetos coletivos, as organizações locais passam a exercer novos papéis, posicionando-se como atores políticos que vão se identificando mutuamente a partir de interações em redes de ampla abrangência social e geográfica, e essa é a forma e o meio pelo qual aos poucos se constitui um movimento social em formação, que tem nas ações coletivas de âmbito local sua força propulsora.

O capital social possibilita a reestruturação do contrato social contemporâneo na perspectiva de reduzir as assimetrias de poder individual, social e territorial, empoderando o cidadão, ou seja, impulsionando um processo, em que pessoas ganham influência e controle sobre suas vidas na perspectiva do desenvolvimento enquanto um processo de expansão de liberdades (PASE, 2006).

Segundo Sen (2002), a necessidade de discutir a valoração de capacidades diversas - que gerem o empoderamento, no que concerne às prioridades públicas, é uma vantagem, pois força a deixar claro quais são os juízos de valor em uma esfera em que esses não podem e não devem ser evitados de vir à tona; a participação pública nesses debates valorativos é na verdade uma parte essencial do exercício de democracia e escolha social responsável. O trabalho da valoração pública não pode ser substituído por alguma suposição engenhosamente brilhante (SEN, 2002).

A inter-relação entre capital social e empoderamento pode contribuir para superar problemas como a situação de pobreza de pessoas e comunidades, transformando as relações de poder em favor daqueles que tinham pouca autoridade para que tenham controle sobre os recursos - físicos, humanos, intelectuais, financeiros e de seu próprio ser - e sobre a ideologia - crenças, valores e atitudes (PASE, 2007).

A tradução da palavra inglesa "empowerment" significa a criação ou a socialização do poder entre os cidadãos e o reforço da cidadania. O processo de empoderamento inclui a conscientização e a participação com determinado grupo ou ao conjunto de uma sociedade. Nesse sentido, empoderamento significa a conquista da condição e da capacidade de participação, inclusão social e exercício da cidadania.

O empoderamento comunitário capacita os "grupos sociais desfavorecidos" para a articulação de seus interesses e participação comunitária, visando à conquista plena dos direitos de cidadania, defesa dos direitos de influenciar ações no Estado (PASE, 2007). Ademais, o entusiasmo ainda em relação ao conceito de capital social relaciona-se a sua potencialidade explicativa ao estabelecer uma nova relação entre a sociedade civil e o Estado, entre o cidadão e o governo, entre o cidadão e o governante ou legislador. Esse conceito possibilita analisar, da perspectiva da ciência política, as possibilidades inovadoras de relação entre as pessoas comuns e o "poder" enquanto tal (PASE, 2006).

A ênfase nos aspectos qualitativos das condições de vida representa a percepção da degradação do 'bem-estar' gerada pela crescente produção de 
mercadorias, a deterioração dos bens naturais comuns e dos serviços públicos básicos e a homogeneização dos padrões de consumo. Isso aponta para uma avaliação do sentido da existência, da qualidade do consumo e da qualidade do trabalho produtivo, que vai além dos problemas de emprego, salário real e da desigualdade na distribuição da riqueza (LEFF, 2001).

O fundamento da facilitação para a transformação através da participação dos atores sociais, com vistas ao logro da melhoria da qualidade de vida desta comunidade foi norteado por três perspectivas:
a) "Poder com",
b) "Poder de dentro "; e
c) "Poder para".

Por meio destas perspectivas pôde-se considerar que essas noções puderam privilegiar a capacidade destes indivíduos em se expressarem e em agirem, em desenvolverem as suas capacidades de realização e, também, em exercitarem a sua liberdade de expressão. Com este exercício se facilitou o processo da participação que envolveu a constituição dos elementos de empoderamento caracterizados por organização comunitária, participação e autoestima. Com essa dinâmica se trabalhou a questão da melhoria da qualidade de vida nesta comunidade.

Especificamente, no que tange à primeira perspectiva supracitada, ou seja, o "poder com" valorizou-se que o envolvimento dos atores sociais nas tomadas de decisões nas reuniões, nas oficinas de devoluções e nas assembleias, foi de suma importância para a conformação da autoestima e também para o favorecimento da compreensão individual estendida para a compreensão coletiva. Portanto, este "poder com" proporcionou a visualização individual, que através dos seus agrupamentos e participações, gerou um aumento do poder para ser utilizado em nome de todos, trazendo benefícios para a própria coletividade.

A segunda perspectiva, o "poder de dentro", referiu-se especificamente ao poder dos indivíduos enquanto atores sociais.

Internamente o ser humano confronta-se constantemente com seus diálogos. Esse fenômeno ficou constatado nas exposições individuais ao longo das conversas e entrevistas e, principalmente, nas participações individuais durante as reuniões e assembleias. Esse "insight" foi tratado como uma potencialidade para a utilização do alcance final da melhoria da qualidade de vida.

A visualização e a posterior compreensão desta dimensão por parte dos indivíduos em relação a este poder particular favoreceu a participação em grupo. Com essa percepção de suas próprias capacidades aflorou, então, a vontade como força individual para dar o suporte necessário à conquista de uma melhor qualidade de vida.

Em respeito à terceira esfera, ou seja, o "poder para", trabalhou-se no sentido de se fazer constantemente circular por entre os atores sociais envolvidos no processo de mudança de suas condições até então, de que estas mudanças, 
quando organizadas de forma participativa, aumentariam a sua autoestima e que isso seria benéfico "para eles" próprios.

Cabe colocar que a sistematização desses elementos constituintes de empoderamento humano, com vistas à melhoria da qualidade de vida desta comunidade excluída social, ambiental e economicamente, também perpassou pelo cerne da questão do "poder sobre" os recursos físicos, humanos, financeiros e das ideologias como crenças, valores e atitudes. Mas, neste particular, se teve o maior cuidado de fazê-lo através do resgate das primeiras três perspectivas usando-as como estratégia para avançar também nesse sentido. Quer dizer: com o uso do "poder com, poder de dentro e do poder para" se praticou a transformação do "poder sobre" os recursos, podendo, a partir daí, manejar os mesmos com a devida equação da compreensão dos reais valores e significados em relação aos problemas sociais, ambientais e econômicos enfrentados pela comunidade na localidade do Passo do Onze à Rua Marcílio Dias.

Essas percepções compuseram a base da essência e do sentido do empoderamento promovido na comunidade, que se constituiu nos elementos que favoreceram e estimularam em direção da melhoria da qualidade de vida. Quer dizer, essas percepções favoreceram o empoderamento e implicaram a mudança nas relações do poder no interior da comunidade e resultaram em propostas de ações mais criativas para a melhoria da qualidade de vida da comunidade.

Com esse envolvimento descrito acima, se foi formando uma rede de atores sociais participativos entre os moradores da rua e a sua associação, também construída nestes moldes, a outros planos da sociedade organizada como, por exemplo, a Prefeitura Municipal, a câmara de vereadores, organizações defensoras do arroio Bagé, imprensa e algumas empresas públicas e privadas. Interesses e conexões também começaram a se desencadear no processo participativo na tentativa de encontrarem alternativas viáveis sob todos os aspectos possíveis para a localidade. A formação desta rede, que essa associação gerou, também proporcionou a visualização do poder coletivo da organização agora dentro de outro plano na sociedade. Com esse novo horizonte coletivo o elemento constituinte de empoderamento, caracterizado por autoestima, promoveu a qualidade de vida.

Essa organização e essa rede que se criou por meio dessas transformações nesta localidade influenciarão outros atores sociais, outras formas de organizações comunitárias e outras formas de participações individuais e coletivas que visem à perspectiva de melhoria da qualidade de vida, com uma concepção sistêmica e sustentável para a consolidação da recuperação de áreas degradadas e manutenção de ecossistemas. Nesse sentido, esse processo poderá futuramente alcançar instâncias maiores, conectando-se formas deste tipo de desenvolvimento local atingindo, posteriormente, bairros da cidade que margeiam o arroio, passando pela cidade, até alcançar uma repercussão de abrangência regional.

Por outro lado, os discursos sociais estão repletos de jargões que, se colocados em alguma ordem, formam um bom texto e/ou argumento e que, invariavelmente, constituem-se por termos como: atores sociais, coletividade, participação, cooperação, colaboração, facilitação, devolução, sustentabilidade, responsabilidade socioambiental, retroalimentação, empoderamento, construção 
coletiva, investigação/ação, ação/reflexão, diagnóstico participativo, oficinas, ações criativas, capital social, qualidade de vida etc. $\mathrm{Na}$ verdade, levando-se em consideração a diversidade social e ambiental existente no planeta, onde aparecem as particularidades de cada uma das comunidades específicas, a mirada e o encaminhamento das sugestões quanto ao melhoramento das condições em geral da vida das pessoas não devem fugir a estas percepções que por ora se estabelecem pelo mundo.

Dentro dessa perspectiva deve-se levar em conta a possibilidade da interpretação de utilização dessas palavras, bem como, e principalmente, da conduta ou do encaminhamento desses conceitos que determinam as performances das organizações locais. A responsabilidade na transferência dessas informações e técnicas para o interior das células coletivas pressupõe a devida compreensão mínima de algumas das consequências que essas atitudes podem desencadear na vida de cada indivíduo ávido por participação.

Villasante (2002) entende que o conceito de desenvolvimento também engendrou uma confusão e que seria preferível substituí-lo por "reequilíbrio", pois esse se ajusta mais às tarefas atuais que a ecologia está demandando da economia. Para ele, é necessário também propor o decrescimento de alguns setores manifestamente nocivos para as comunidades vivas e, ao mesmo tempo, a reestruturação de outros setores e, finalmente, a expansão daqueles de tecnologias brandas, baseadas em recursos renováveis, isso sob a responsabilidade dos próprios implicados.

Além de todo o cuidado em compor-se uma postura que demonstre integração, interação e respeito aos demais envolvidos nesses processos de "construções coletivas", é vital a concepção não apenas sistêmica, se é que seja possível, mas da possibilidade de se poder passar a conviver com a ineficácia também deste modelo alternativo. Quer dizer, a simples sugestão, o simples encaminhamento, a simples condução de processo participativo, não garante resultados entendidos e/ou almejados como "melhorias".

Há que se levar também em consideração o princípio da respeitabilidade, ou seja, pode que os "atores sociais" simplesmente não queiram mudar. E deve-se, portanto, respeitá-los por isso e deixar de lado o afã de querer induzir a participar/transformar uma realidade.

Nesta torrente que atravessa as transições sociais e suas demandas, claramente estão as consequências do modelo de desenvolvimento desordenado em vigor, principalmente nas últimas décadas. As alterações ambientais e as acelerações quantitativas, no que tange à formação de resíduos, e a exclusão social constituíram-se nos principais indicadores do desenvolvimento sob estas políticas. Com base nesses fatos, urge a necessidade de alternativas que procurem preservar condições possíveis para a atualidade e para as gerações futuras. Daí, a perspectiva do "desenvolvimento sustentável".

Apreendendo esse movimento começam a conectar-se os pontos identificados e a formar-se redes que são imediatamente reconhecidas como impreteríveis na constituição deste mais novo processo social. A importância dessas redes está em suas várias possibilidades como ferramenta. Uma de suas principais 
características e benefícios ao processo está na sua capacidade de favorecer a retroalimentação das informações/ações e reflexões. Esse exercício realmente empodera. Empodera no sentido de que gera um estado de compreensão individual da dimensão da situação em vivência pelo grupo como um todo. E este é o diferencial destas alternativas aos modelos anteriores. Esse diferencial por ora é significativamente mais adequado e isto tem como base os comportamentos verificados nos envolvidos em processos deste estilo. Este é o primeiro degrau para se alcançar uma melhora.

A tangibilidade percebida através da compreensão que atinge uma coletividade por meio desse diferencial proporciona novas condições às sugestões alternativas e, também, mais criativas, propostas para a consecução das soluções identificadas pelas comunidades ante os seus próprios problemas. E isso empodera mais ainda.

Esse conjunto de ações pode se conectar a outros grupos e estabeleceremse vínculos, interesses, parcerias, ampliando este sistema infinitamente. As interligações organizacionais transferem-se com este movimento ampliando-se também com esta qualificação. E essas ligações, que fundamentam e constituem propriamente as redes sociais, também consolidam e proporcionam 0 empoderamento ao processo e aos envolvidos.

Nesta localidade constatou-se um ambiente socialmente desestruturado em termos de organização, carente em relação a possibilidades econômicas, e degradado no que diz respeito ao meio ambiente que o circunda.

Algumas tentativas de caráter convencional foram implantadas nesta localidade, mas seus resultados apresentaram-se insatisfatórios, conforme depoimentos dos próprios atores sociais.

Essa conjuntura favoreceu a implantação da investigação-ação-participação como estratégia viável de desenvolvimento de práticas que promovessem o empoderamento individual e coletivo.

O afloramento dessa sensação por meio da participação coletiva proporcionou a autocompreensão e a autoidentificação desta comunidade no tempo e no espaço conectando-a e, portanto, valorizando-a enquanto constituída de cidadãos conscientes. A apreensão desta "capacidade" de resolver seus próprios problemas não tinha sido favorecida e/ou desenvolvida com esta potencialidade e/ou plenitude nesta localidade. Com "estas percepções destas práxis instituídas abriram-se novas formas de fazer-se ciências sociais de maneira criativa" (VILLASANTE, 2002, p. 149).

Esta práxis desencadeou o surgimento de uma rede. Este processo se alastrou para fora da comunidade, se conectou e atingiu outras formas de organizações estabelecidas e estimulou a formação de outros grupos para que se associassem e buscassem com base nestes princípios alternativos, ações criativas para seus próprios problemas. Villasante (2002) afirma que o mais importante é que este processo transformador foi fundamental por respeitar e dar-se ao ritmo das pessoas. Esse comportamento respeitoso, presenciado e facilitado pelo método participativo, ampliou a desenvoltura e o empoderamento. Com esta base em relação às transformações nesta localidade, "o que validamos ou avaliamos não foi 
tanto se mudaram os sujeitos, mas foi constatar se mudaram as sujeições e qual foi o novo sentido que adquiriram, ou seja, se cada grupo ou pessoa pode refletir sobre a sua práxis e decidir por onde quis continuar na construção da sua cidadania e do seu viver melhor", conforme colocado por Villasante (2002, p. 117).

Avaliaram-se os aspectos materiais e ganhos estruturais que por ventura identificavam objetivos por parte da comunidade. A finalidade dessa avaliação foi que, por vezes, se trabalhou utilizando estes objetos como "ferramentas estratégicas" tomando-se cautela para evitar a geração de expectativas que pudessem ser frustrantes, quer dizer, se trabalhou essa questão como um meio para alcançar o aglutinamento que proporcionasse o debate e o diálogo entre os atores para, a partir daí, construir com as suas potencialidades e as suas ideias mais criativas as ações e as relações que garantiriam as efetivações, quiçá destes mesmos objetos escolhidos pelos próprios atores sociais desta parte da Rua em questão, pois se considerou, primeiramente, a conformação do empoderamento, para, posteriormente se utilizar desta capacitação por se acreditar ser muito mais eficiente se racionalizada desta forma e nesta ordem. Um estilo de tratamento e de (rel)ações começou a se estabelecer entre os atores, onde as decisões foram se tomando e se inovando conforme os problemas foram surgindo, apesar de se trabalhar com metas e propostas coletivas de ações mais criativas como um "norte" a ser seguido pelo grupo.

Então, o cerne desta proposta esteve prioritariamente na transformação via debate e diálogo entre a sociedade e os atores sociais diretamente envolvidos na investigação, que, neste caso específico, foi a comunidade do Passo do Onze no segmento da Rua Marcílio Dias, para construir opções estratégicas coletivas que respondessem a uma necessidade de transformação de problemas, que considerasse também a complexidade, bem como a instabilidade social local e a importância desta localidade como detentora de um ecossistema fundamental para toda a microrregião, e que precisava ser enfocado sob um novo prisma.

A consideração do capital social local como suporte foi fundamental dentro deste processo participativo porque tornou este projeto mais criativo/reflexivo e mais eficiente, pois contou com muitos atores que normalmente não eram considerados em seus aportes para a planificação e execução de propostas eficazes para encarar a complexidade da recuperação do arroio Bagé. Essa implicação simples, porém fundamental, devido a sua pluralidade e diversidade de interesses e propostas sociais e culturais utilizadas como ferramentas pelos atores envolvidos na busca pelas alternativas, quando nas construções coletivas das metas e estratégias de enfrentamento dos problemas da localidade, enriqueceram o processo.

Este processo construído e constituído coletivamente abriu um novo cenário de possibilidades para a comunidade em questão. A partir do seu empoderamento com base na sua nova organização social, pautado na participação e no aumento de autoconfiança neste empreendimento, se abriu o leque para a formação de uma rede de cooperadores/colaboradores/parceiros/facilitadores e a localidade passou a ser mirada sob uma nova perspectiva.

O processo investigatório que se desenvolveu, com base na observação participante, entrevistas e reuniões com a comunidade geraram informações sobre 
o estado da autoconfiança individualmente, bem como também em termos de grupos, e de comunidade.

Com o auxílio da metodologia da investigação-ação-participação houve algum aclaramento quanto às potencialidades coletivas e pôde-se perceber certa coesão interna e certo sentido de solidariedade. Depois do processo houve também um restabelecimento da discussão e da análise crítica, o que proporcionou também um estímulo ao empoderamento. Todavia esses podiam ser fenômenos efêmeros e com base apenas no fato de a comunidade ter sido objeto de uma investigação, ou seja, não assegura a transformação crítica das pessoas e das suas ações em relação ao seu meio de forma consistente.

Observe-se que foram obtidos resultados de caráter social em consideração à participação e à integração com a sociedade, bem como uma maior participação desta comunidade em processos de cunho social na busca das causas que dissessem respeito ao arroio Bagé. A sensibilização dos agentes administrativos, da esfera municipal, para a questão estratégica da limpeza dos recursos hídricos para usufruto da população em médio e, principalmente, longo prazos, foi abordada e também praticada. Ou seja, coletivamente se construiu as informações relativas a esta localidade, se utilizou das mesmas e se integrou socialmente via criação de um laço entre algumas esferas da sociedade organizada, como a prefeitura e outras empresas.

Em relação aos resultados de caráter econômico, procurou-se reativar a memória sobre atividades ou ações que culturalmente foram interrompidas e que poderiam resultar em geração de renda alternativa mediante a recuperação do arroio, como por exemplo, a lavagem de roupas. Contudo, essas são etapas que poderão ser efetivadas em outras margens do arroio, mas dependem da participação e do desencadeamento deste processo participativo iniciado no Passo do Onze para que se estabeleça e se estabilize o método participação-ação como elemento chave capaz de disseminar a viabilidade, a capacidade e a real possibilidade de concretização dessas ações futuras entre os demais ribeirinhos do arroio a jusante e a montante.

Outro ponto a se considerar, no que tange a resultados de caráter econômico, se refere ao aspecto visual das margens do arroio, principalmente dentro da zona urbana. Essa questão terá maiores expressões a médio e longo prazo, na medida em que a estratégia principiada na localidade do Passo do Onze for expandida nos dois sentidos do arroio (montante e jusante) e quando este trabalho desencadeado trouxer, para outros atores sociais que se envolverão, uma nova perspectiva de desenvolvimento sustentável às margens do arroio Bagé.

Resultados de caráter ambiental se realizaram na medida em que a comunidade se sensibilizou mais, conforme os debates e diálogos foram se sucedendo durante as entrevistas, reuniões, conversas e oficinas de devoluções criativas em relação à biodiversidade que os envolve.

Não se conseguiu, em curto prazo, uma mudança na maioria dos integrantes da comunidade no que se refere à redução de descarte de resíduos sólidos nas margens e no próprio arroio, mas se conseguiu, via associação e seus representantes, o começo de um trabalho através de propostas coletivas mais 
criativas que envolverão gradativamente, conforme estratégia e proposta, a maioria e, quiçá, toda a comunidade do Passo do Onze, à Rua Marcílio Dias, com a inserção de locais e recipientes mais adequados para a receptação dos resíduos.

Essa consciência coletiva, aclarada pela construção de quem participou neste processo, foi o grande diferencial e que ensejou apropriadamente a verdadeira transformação social necessária nestes tempos na localidade do Passo do Onze, na Canhada do Sapo, à Rua Marcílio Dias, em Bagé.

Esse novo processo alterou definitivamente a consciência coletiva e isso promoveu também uma alteração quanto à perspectiva de melhoria na qualidade de suas vidas. Essa "transformação" poderá ser utilizada como ferramenta de suporte e de desencadeamento em outras localidades para conformarem um universo maior através de uma rede de pequenas comunidades envolvidas na (re)estruturação de um novo modelo de desenvolvimento regional mais participativo e sustentável.

A principal deficiência disse respeito à incapacidade de auto organização e de manutenção do processo participativo que foi verificado. Nesse sentido, apareceram como novos problemas a serem enfrentados pela comunidade da rua.

Porém, constatou-se após a realização da segunda série de entrevistas semiestruturadas que a comunidade se empoderou, pois a mesma compreendeu relativamente a importância de uma gestão local. Além disso, participou coletivamente do processo e retroalimentou-se das suas colocações e dúvidas e discutiu alternativas que dissessem respeito à sua melhoria de qualidade de vida. Participou da construção coletiva da sua Associação. Construiu, também de forma coletiva, estratégias, bem como atividades sustentáveis para a manutenção do seu entorno. Adquiriu coletivamente maior consciência da importância estratégica do lugar onde vivem como ecossistema essencial para a recuperação do arroio Bagé. Aceitou a provocação de participar do processo investigatório. $E$, finalmente, 0 grupo aceitou participar de um processo coletivo que, em tese, promoveu uma nova perspectiva de uma transição ambiental, social e econômica e que visou criar um fundamento para o desencadeamento do desenvolvimento regional, partindo desta base local.

A pesquisa/ação nesta localidade proporcionou uma transformação social no que diz respeito à organização da população local. Esta organização, primeiramente em caráter individual e depois em caráter coletivo, empoderou a comunidade, e isso favoreceu uma mudança em relação à perspectiva de enfrentamento dos problemas.

\section{REFERÊNCIAS}

CHIZZOTTI, A.: Pesquisa qualitativa em ciências humanas e sociais. Petrópolis, RJ: Vozes, 2006.

LEFF, E.: Epistemologia ambiental. São Paulo, Cortez, 2001. 
VILLASANTE, T. R.: Redes e alternativas: Estratégias e estilos criativos na complexidade social. Petrópolis, RJ: Editora Vozes, 2002.

MONZÓ, E.: "Capital social, herramienta para los programas de superación de la pobreza urbana y rural". Estrategias individuales y colectivas de capital social: el impacto de programas públicos en dos comunidades campesinas. Los casos de Ajial de Quiles y Cerro Blanco, VI Región de Chile. CEPAL, 2003.

PASE, H. L., Capital social e empoderamento. Disponível em: $<$ http://www.sociologia.ufsc.br/npms/hemerson_luiz_pase.pdf>. Acesso em: 15 ago. 2007.

Capital social e desenvolvimento rural no Rio Grande do Sul. Tese de doutorado, Instituto de Filosofia e Ciências Humanas, Programa de Pós Graduação em Ciência Política, Universidade Federal do Rio Grande do Sul, UFRGS, Porto Alegre/RS, 2006.

SEN, A.: Desenvolvimento como liberdade. São Paulo, Companhia das Letras, 2000.

Submetido em 10/01/2012

Aprovado em 20/03/2014

Sobre o autor

Jaime Quintanilha Gomes

Doutor em Desenvolvimento Regional pela Universidade de Santa Cruz do Sul, Brasil, Universidad de Córdoba, Espanha. Mestre em Agroecologia e Desenvolvimento Rural Sustentável - Universidad Internacional da Andalucía, Espanha. Especialista em Administração de Empresas pela Universidade da Região da Campanha e Universidade Federal de Santa Maria. Administrador de Empresas da ELETROBRAS/CGTEE, Companhia de Geração Térmica de Energia Elétrica em Candiota/RS.

Endereço: Rua Miguel Arlindo Câmara, 3601. CEP 96495-000 - Candiota, RS - Brasil.

E-mail: jaimeq@cgtee.gov.br 